\title{
The Noticing Function of Output in Acquisition of Rhetorical Structure of Contrast Paragraphs of Iranian EFL University Students
}

\author{
Hassan Soleimani (Payame Noor University)/Saeed Ketabi/Mohammad Reza \\ Talebinejad (Isfahan University)
}

\begin{abstract}
This article is an attempt to contribute to the growing body of research investigating the noticing function of output (cf. Swain 1995 in Izumi/Bigelow 2000: 239), and more specifically the use of output-fronted activities that might prompt FL learners to notice their linguistic problems to facilitate their gain of rhetorical structure of contrast paragraphs in English. Three groups of EFL learners participated in the study. Two groups (the experimental group and comparison group 1) were required to initially produce a paragraph (output 1), then they received a model contrast paragraph to underline, and finally they were asked to produce a contrast paragraph (output 2). For the experimental group, the topic to write was a contrast topic; whereas, the comparison group were to write on a non-contrast topic. The third group (the preemptive comparison group 2) received the teacher's deductive instruction and explanation of contrast paragraphs in English followed by an output to produce a contrast-related paragraph. The results indicated considerable effect of outputfronted activities on learners' noticing the targeted structures and forms. In addition, the output-first-then-input activities were found to be much more effective than pre-emptive input activities.
\end{abstract}

\section{$1 \quad$ Introduction}

Questions that have remained central for psycholinguists since second language acquisition emerged as a discipline in the 1970s as a field of inquiry in its own right centre around issues as what cognitive processes underlie success and failure in learners' attempts to master the linguistic patterning of a second language (L2), how general mechanisms of memory and attention are involved in second language acquisition, and how they contribute to language acquisition. In recent years, a number of researchers have attempted to present fully elaborated, cognitively oriented frameworks for thinking about SLA (e. g., Gass 1997, Johnson 1996, Skehan 1998, Van Patten 1993). These works build upon earlier efforts to bring an information-processing orientation to the SLA field (e. g., McLaughlin 1987, McLaughlin/Rossman/McLeod 1983, McLeod/McLaughlin 1986), and they draw upon theories of attention, memory, and skill to be found in both the SLA and general cognitive psychology literatures (cf. Segalowitz/Lightbown 1999).

Specifically speaking, the questions which serve as departure points for second language acquisition research and pedagogy over the two past decades have been whether the process of acquiring an L2 is a conscious or subconscious process, and whether consciousness is necessary at all in the process of internalization of information. Different positions have been 
identified. According to Krashen's Acquisition Hypothesis (1983), acquisition takes place subconsciously; however, to Schmidt (Noticing Hypothesis, 1994) acquisition is largely a conscious process (cf. Izumi/Bigelow 2000: 240). Tomlin/Villa (1994) claim that acquisition is in part conscious and in part subconscious (cf. Hulstijn/Schmidt 1994: 7). So, the role of attention has recently too much preoccupied SLA researchers, psycholinguists, and cognitive psychologists (McLaughlin/Heredia 1996; Sharwood Smith 1993; Long 1991; Ellis 1994; Schmidt 1994, 2001) to theorize how input changes into intake.

In addition to exposure to input and requirements for input to change into intake, equally important is recognizing by the researchers the role of output in the process of second language acquisition. Schmidt (1992) has stated the need for learners to engage with language in their own output which is similarly developmental, so that by readily calling on a rich linguistic repertoire they can progressively 'automatize' their knowledge. As with new intake, the learners' early efforts to output new forms are likely to require conscious attention, since the ease with which competent users call on language in their output is something which is only gradually accomplished (cf. Hulstijn/Schmidt 1994: 1-2). Because of this, and also because such output often requires the selection of a more complex and challenging form over a simpler paraphrase, it is sometimes known as 'pushed output' (cf. Swain 1985 in Izumi/Bigelow 2000: 244). According to Izumi (2002), pushed output, by virtue of producing utterances, can place the learner in an ideal position to make a cognitive comparison between the IL and TL forms. In short, pushed output can induce the learners to process the output effectively for their greater interlanguage development. Output may lead to greater metalinguistic awareness. In the process of striving to produce output that their interlocutors will understand, learners may pay particular attention to form, and may notice a gap between what they want to say and what they can say, leading them to recognize what they do not know, or know only partially (cf. Swain 1995 in Izumi/Bigelow 2000: 244).

\section{Theoretical Background}

\subsection{Attention and Second Language Acquisition Research}

In fact, in classical psychology, attention and consciousness are often viewed as two sides of the same coin. As Carr/Curran (1994) point out, "if you are conscious of something, then you are attending to it... and if you are attending to something, then you are conscious of it" (cited in Al-Hejin 2002). Moreover, everyday use of the term conscious has a variety of overlapping meanings such as awake, aware, and deliberate. The reason for this overlap, as the following discussion will illustrate, is that these concepts are inherently connected, and one concept often entails the other.

Schmidt (1994) identifies four dimensions to the concept of consciousness. The first is intention, which refers to learner's deliberateness to attend to the stimulus. Intention is often associated with intentional versus incidental learning. The second dimension of consciousness is attention, which basically refers to the detection of a stimulus. The third aspect of consciousness is awareness, which refers to the learner's knowledge or subjective experience that $\mathrm{s} / \mathrm{he}$ is detecting a stimulus. Awareness is often associated with explicit versus implicit learning, since learners may or may not be aware that they have acquired a new structure (e. $\mathrm{g}$, children generally seem unaware of the complex syntactic rules they acquire). The fourth dimension of consciousness is control, which refers to the extent to which the language learner's output is controlled, requiring considerable mental processing effort, or spontaneous, requiring little mental processing effort (cf. Hulstijn/Schmidt 1994: 5-11).

Another group of second language acquisition researchers (Tomlin/Villa 1994) claim that detection, attention without conscious awareness or noticing, is a key process in second 
language acquisition (cf. Bärenfänger et al. 2002: 1). Tomlin/Villa (1996) assert that detected information can be registered in memory and disassociated from awareness. Sharwood Smith (1993) intended to facilitate the learner's selection process of input by increasing the perceptual saliency of specific targeted forms in the input. This process would appear to engage the learner's attention as a selective process as it involves directing the learners focal attention to a specific form from an array of verbal or written forms. Another point Sharwood Smith (1993) emphasizes in his rationale for Input Enhancement is the possibility of increasing the saliency of a selected form in order to promote the restructuring of a the learners developing interlanguage system. This would seem to involve not only the process of selective attention, but also the way in which the form is to be subsequently processed by the working, short-term memory and long-term memory (cf. Sharwood Smith 1994: 178-180).

\subsection{Comprehensible Output Hypothesis}

It seems to be universally accepted that SLA is dependent on input (cf. Krashen 1985 in Shehadah 2003: 155-157). The earlier studies of input examined what is available to language learners and what part of input is relevant in language learning. The former issue led to studies of modified speech such as caretaker talk, foreigner talk, and teacher talk. The latter was investigated in terms of comprehensible input hypothesis. Krashen $(1982,1985)$ claims that humans learn a language only by receiving enough comprehensible input which is called the Input Hypothesis. What is crucial in language development is $i+1$, or the input that contains structures of the learner's next level. That is, the input learners expose to must be a little beyond the learners' existing level to prompt acquisition (cf. Shehadah 2003: 155-157).

In the literature of second language acquisition research, research on noticing in L2 acquisition has largely focused on input, and little attention is paid to the role of output in facilitating language acquisition. In a seminal article, Swain (1985) argued that comprehensible input may not be sufficient for successful second language acquisition, but that opportunities for nonnative speakers to produce comprehensible output are also necessary. Swain based her conclusions on findings from studies she conducted in immersion contexts in Canada. She found that although immersion students were provided with a rich source of comprehensible input, their interlanguage performance was still off-target; that is, they were clearly identifiable as nonnative speakers or writers. In particular, Swain found that the expressive performance of these students was far weaker than that of same-aged native speakers of French. For example, they evidenced less knowledge and control of complex grammar, less precision in their overall use of vocabulary and morphosyntax, and lower accuracy in pronunciation. Thus, Swain claimed that understanding new forms is not enough and that learners must also be given the opportunity to produce them. She proposed a hypothesis relating to the second language learner's production comparable to Krashen's comprehensible input hypothesis termed as the Comprehensible Output Hypothesis for SLA. Swain argued that comprehensible output is the output that extends the linguistic repertoire of the learner as he or she attempts to create precisely and appropriately the meaning desired. She argued further that the role of learner production is independent in many ways of the role of comprehensible input, claiming that $\mathrm{CO}$ hypothesis is also a necessary mechanism which aids SLA in many ways. In a nutshell, Swain's (1985) CO hypothesis predicts that we acquire language when there is a communicative breakdown and we are "pushed to use alternative means to get across the message precisely, coherently, and appropriately" (cited in Krashen 1998: 179).

Since the output hypothesis was first proposed, Swain has refined her hypothesis and specified the following four functions of output. First, output provides opportunities for developing automaticity in language use. This is the fluency function. In order to develop speedy access to extant L2 knowledge for fluent productive performance, learners need 
opportunities to use their knowledge in meaningful contexts, and this naturally requires output. The second function of output is a hypothesis-testing function. Producing output is one way testing one's hypothesis about the target language. Learners can judge the comprehensibility and linguistic well-formedness of their interlanguage utterances against feedback obtained from their interlocutors. Third, output has a meta-linguistic function. Swain (1995) claimes that "as learners reflect upon their own TL use, their output serves a metalinguistic function, enabling them to control and internalize linguistic knowledge" (cited in Izumi/Bigelow 2000: 245). In other words, output processes enable learners not only to reveal their hypotheses, but also to reflect on them using language. Reflection on language may deepend the learners' awareness of forms, rules, and form-function relationships if the context of production is communicative in nature. Finally, output serves as a noticing/triggering (or consciousness-raising) function. According to Swain (1995), in producing the TL learners "may notice a gap between what they want to say and what they can say, leading them to recognize what they do not know, or know only partially" (cited in Izumi/Bigelow 2000: 244). The recognition of problems may then prompt the learners to attend to the relevant information in the input, which will trigger their IL development.

Evidence from research that supports some of the functions of the output hypothesis suggests that output might indeed be beneficial for SLA. Izumi/Bigelow (2000) compared an experimental group, which received input via written exposure to the target form and engaged in output tasks, to a comparison group, which received the same exposure to the target form but did not engage in output. With only one exception, in which the experimental group outperformed the comparison group, there were no statistical differences between groups on any measure. The general lack of difference between groups was attributed to task demands rather than the learning conditions. Following a similar study design, but one that reduced task demands, Izumi/Bigelow (2000) compared four experimental groups (composed of combinations of 6 output and 6 input enhancement) and a control group. The output groups engaged in a text reconstruction task, whereas the control groups answered extension questions based on the text. Results indicated that participants in the output groups used the target form in the reconstruction tasks and outperformed non-output and control groups on posttest measures (cf. Morgan-Short/Bowden 2006: 38).

Horibe (2002) conducted a study which compared two instructional treatment conditions (input only and input + output) to examine the effects of opportunities for output on the acquisition of the target forms, which were several syntactic structures. The subjects' thought processes in spoken output were elicited in think-aloud protocol interviews. Study participants were 31 college students in a Japanese course in 3 intact classes: input only (input group), input and output (output group), and no instruction (control group). The results indicated no 18 statistically significant difference between the input group and the output group in terms of the acquisition rates of the target forms (cf. in Lluna-Mateu 2006: 17).

A study by Nobuyoshi/Ellis (1993) provided data showing that comprehensible output results in actual improvement. In their study, six adult EFL students in Japan were asked to participate in a jigsaw task with their teacher in which they described actions in pictures that, they were told, occurred the previous weekend or previous day. Nobuyoshi/Ellis (1993) concluded that their study provided "some support for the claim that 'pushing' learners to improve the accuracy of their production results not only in immediate improved performance but also in gains in accuracy over time" (cited in Krashen 1998: 178).

To sum up the literature, the majority of studies mentioned focused on output and its role in acquisition and little attention was paid to the noticing function of output. In fact, it appears that the missing point is the noticing nature of output which facilitates the learning process. 
Considering the shortage mentioned, the present study made an attempt to investigate the issue of output in terms of its noticing effect in the acquisition of specific targeted forms and items.

\section{$3 \quad$ Research Questions and Hypotheses}

Considering the issues mentioned in the literature, the present research follows up on Izumi and Bigelow's (2000) study in an attempt to shed light on the learners' psycholinguistic processes as involved in output fronted activities. Izumi and Bigelow's study focused on the acquisition of one specific type of conditionals while the focus of this study was on the acquisition of rhetorical structure or text structure of a particular type of expository text, namely contrast paragraphs in English. The study outlined in this paper was designed to provide answers to the following questions:

Question 1: Do output-first-then-input activities promote learners' noticing the rhetorical structures of contrast paragraphs?

Question 2: Do output-fronted activities result in the immediate improvement of production of the target rhetorical structures?

Question 3: Do the output-first group learners outperform the non-output-first group learners?

Taking these questions into account, the following hypotheses were formulated:

Hypothesis 1: Producing output will enhance greater noticing of the target rhetorical structures contained in the input.

Hypothesis 2: The noticing function of output will significantly affect acquisition of rhetorical structures of contrast paragraphs in English.

Hypothesis 3: The output-first group learners outperform the non-output-first group learners (pre-emptive group learners) concerning the acquisition of targeted forms.

\section{$4 \quad$ Method}

\subsection{Participants}

For the purpose of the present study, there were initially 75 participants, but 12 of them had to be excluded from data analyses, since they failed to complete the Output 2 parts; therefore, the data analyzed come from 63 subjects. The participants ranged from early 20 to 25 years of age. $14 \%(\mathrm{~N}=9)$ were males and $85 \%(\mathrm{~N}=54)$ were females. All study participants were L1 Persian speakers studying English as a Foreign Language enrolled in the same university (Qom Azad University, Iran). All were second-year students taking part in an obligatory writing course entitled "Advanced Writing", the purpose of which was asserted to instruct paragraph writing in English. Placement of the subjects into the classes was based on the enrollment procedures of the university and students' passing the preparatory grammar courses. The students from the 3 intact classes randomly selected from 6 available classes had to have been present for all phases of the experiment: for the pretest, Output 1 session, the instructional treatment, and the Output 2 session.

To verify that the participants at each of the classes were homogeneous in terms of proficiency, they were administered a Cambridge English Placement Test (CEPT). The mean scores of each group on the test were analyzed. The results of a least significant difference (LSD) test, 3 with alpha set at .05, indicated no statistically significant difference among the CEPT test scores of the three classes. Thus the test confirmed that the students within the groups were at the same level of English proficiency. The participants in the study did not 
receive funding for participating in the study. It was at the discretion of their respective instructors to decide whether they would be given extra credit.

\subsection{Research Design and Procedure}

To examine the research hypotheses, a comparison group design was employed. Three groups were established: one experimental group and two comparison groups (see Figure 1 for the overall research design). The groups were three intact classes randomly selected from among 6 available classes, and their homogeneity was verified utilizing the LSD analysis. All the subjects in the experimental group and comparison group 1 were required to produce an output first, except comparison group 2 (non-output or pre-emptive group) learners who started with their instructor's input. All the participants in the experimental and comparison groups were thoroughly informed of the procedures to be followed throughout the study prior to the tasks.

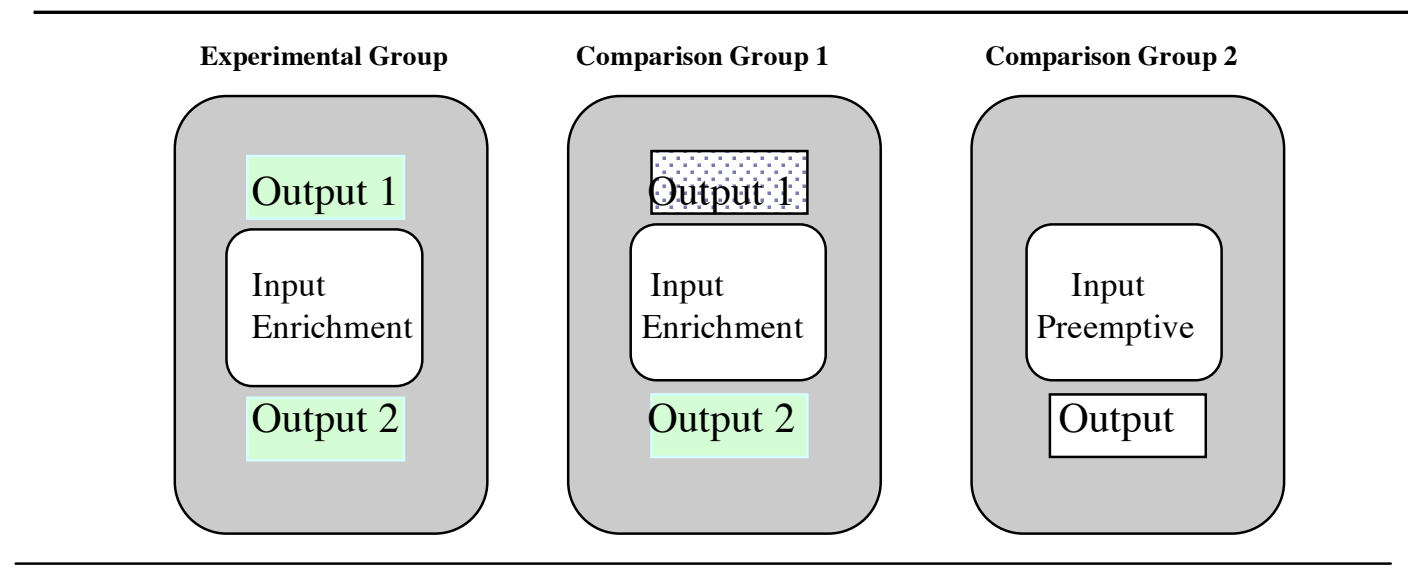

Figure 1: Overall Research Design (Comparison Group Design)

\subsection{The Rhetorical Structure of Contrast}

In the present study, the target forms to be focused were the rhetorical structures used in typical contrast paragraphs in English. Following Taboada and Mann's (2006) Rhetorical Structure Theory (RST) and examining the paragraph writing and essay writing textbooks in English (in particular Refining Composition Skills by Smalley/Rutten/Kozyrev (2001: 17175); Paragraph Development by Arnaudet/Barrett (1981: 140-143), the most frequently used rhetorical forms used in English contrast paragraphs were selected as followings:

T-units (including clauses of contrast using subordinators as although, whereas, etc.) -er...than; more...than; less...than

punctuation (;)

coordinate conjunctions (but, yet)

predicate structures (to differ from, to contrast with)

sentence connectors (however, nevertheless, in contrast, conversely, on the other

hand)

prepositions (different from, unlike, in contrast to, contrary to, as opposed to) 


\subsection{Experimental Group}

As illustrated in Figure 1, all the participants in the experimental group were given an opportunity to produce a paragraph. To meet the requirements of the study, the topic was selected by the researchers to function as a prompt for the subjects to elicit the desired rhetorical structures frequently used in English contrast paragraphs: "The Differences between Men and Women in Iran." The researchers selected this topic due to their personal teaching experiences in actual paragraph writing and essay writing courses in universities. Students in those classes are ordinarily observed feel at ease with this topic perhaps because no specific background or prior schemata is required to develop the topic. No limitation was announced concerning the length of their paragraphs, but they were told to name at least three differences. The maximum time allotted to complete the task was 30 minutes, but nearly all the participants finished their task in less time than the allotted one.

Having completed their first paragraphs, the participants were asked to submit their paper to the instructor, in this phase one of the researchers. Next, the researcher handed out a model paragraph of contrast by a native speaker among the participants (see the Materials section for the details). The model paragraph contained a variety of contrast forms which are typically used in academic contrast paragraphs. The participants in the experimental group were told to read the paragraph carefully and underline the parts of the input to help in their second writing attempt. They were required to underline every thing they thought would help them in their rewriting task from punctuation to a whole sentence. Again for this phase of reading and underlining the input model paragraph, no time limitation was allotted. The participants completed the task in approximately 10 minutes in average.

In the third phase of the treatment, the participants were required to write their second output. Here again, they were to rewrite on the same topic assigned formerly: "The differences between Men and Women in Iran." To produce their second output, the participants were again given as much time as they demanded. Moreover, they were asked to mention at least three differences to fulfill the requirements of length of their output. They were also announced misspelling would not be penalized. In approximately 30 minutes in average, they accomplished their second output.

\subsection{Comparison Group 1}

As shown in Figure 1, all the 19 subjects taking part in the study as Comparison Group 1 began with their output 1 . In fact, they were required to write a paragraph. In this case, however, the topic of the paragraph was different from the topic assigned to the experimental group: "The characteristics of Good Students." No limitation was announced concerning the length of their paragraphs. The rest of the procedure used with Comparison Group 1 was exactly the same as the procedure applied to the Experimental Group: they were presented with the same model contrast paragraph to read carefully and underline, and they were asked to produce their second output using the same topic used with the experimental group.

\subsection{Comparison Group 2: Pre-emptive Input}

Within the category of incidental focus on form, Ellis/Basturkmen/Loewen (2001) distinguished between pre-emptive and reactive techniques. In pre-emptive focus on form, the teacher draws the learner's attention to a form before a problem arises. The teacher briefly treats language as an object and may or may not use meta-linguistic terminology. Following Ellis, in the comparison group 2, the study procedure started with the teacher's explicit teaching of paragraphs of contrast. In fact, using the deductive method, the teacher started with the definition of contrast paragraphs. Then, applying syntactic terminologies, she enumerated the types of contrast structures frequently used in English contrast paragraphs. A 
model sentence followed each explanation of the pattern. The explanations and the model sentences were basically selected from students' textbook entitled Paragraph Development by Arnaudet/Barret (1981: 140-143). After explaining the contrast structures accompanied with model sentences, the instructor presented the learners with a complete model paragraph of contrast from their textbook, and analyzed the structures of contrast already explained.

The instructor's teaching having finished, she handed out predetermined blank sheets with a topic. The participants were required to write a paragraph of contrast on the topic similar to the experimental group's topic: "The differences between Men and Women in Iran". The allotted time for them to complete their output was 30 minutes (in approximately 30 minutes in average, they accomplished their second output), and similar to the participants in the experimental group, they were told to explain at least three differences in their paragraphs. Furthermore, they were free to ask unknown words in English, and no penalty was given to their misspellings.

\subsection{Materials and Data Collection}

Two types of materials were used to collect the necessary data for the purpose of the study: the participants' outputs which involved their written paragraphs and the model contrast paragraph which was selected to be underlined by the subjects. The model contrast paragraph was a paragraph of approximately 200 words written by a native speaker to contrast Arizona and Rhode Island. The researchers decided to select the model paragraph used, from among many selected paragraphs, mostly due to its conformity with could be called typical academic contrast paragraphs: it enjoyed a good topic, coherence, cohesion, and supporting ideas (see Appendix A for the model contrast paragraph). Moreover, the model paragraph seemed to be a rich one in terms of contrast rhetorical structure. In each sentence of the paragraph would learners notice contrast structures and lexemes. Consequently, it appeared that the model paragraph was in congruity with Sharwood Smith's input enhancement model. The second comparison group (the pre-emptive input group) received a lesson in contrast from their textbook. In the lesson were the explanation of a contrast paragraph, a model contrast paragraph, numerous contrast structures and patterns, and some exercises.

\subsection{Data Analysis}

To examine the research hypotheses, the data were collected using a two-fold instrumentation procedure: the participants' written outputs during the experimentation and their underlining.

To score the participants' written output throughout the study, a scoring module was designed (see Appendix B for the scoring module). According to Norris/Ortega (2003), "an interpretation is warranted when researchers can demonstrate that a measure has provided trustworthy evidence about the construct it was intended to measure" (cited in Doughty/Long 2003: 722). They mentioned two major threats to construct validity in measurement: construct underrepresentation and construct-irrelevant variance. For the purpose of this study, since we focused on the acquisition of rhetorical structure of an academic contrast paragraph, contrastrelated items were defined as follows: 1) Topic sentence involving topic existence and topic effectiveness; 2) Topic development involving clarity of expressions of ideas and overall effectiveness of the whole paragraph; and 3) Contrast-related structures and items involving the number of error-free T-units, unique contrast lexemes, punctuation, coordinate conjunctions, predicate structures, and sentence connectors. In the present study, the use of the above mentioned structures and items by subjects in their outputs were indicative of their learning the structures.

Each participant's production score was computed as follows: the first section of the module consisted of items arranged to meet the requirements of organization and coherence needed in 
the rhetorical structure of contrast paragraphs. For this purpose, an ordinal three-scale Likert was designed to meet the requirements of topic, cohesion, and coherence of each paragraph. To score the second section, the frequency of use of each of the contrast-related items was computed for each participant's output. One point was assigned for each item used by the subjects. At first, two of the researchers scored two papers collaboratively to come up with the desired conformity in scoring, and then all the produced outputs were scored by the two researchers separately.

In order to assess the participants noticing of the target rhetorical structures used in contrast paragraphs, the participants in the experimental group and the first comparison group were asked to underline parts of the passage they thought necessary in their reproduction. According to Izumi/Bigelow (2000), using underlining as measure of noticing would be advantageous owing to the fact that it could be considered as an on-line measure to tap the participants' attentional processes in the real time of the task. They believe, "they have an advantage over postexposure measures of noticing because they allow more direct access to learners' ongoing internal processes and minimize possible memory loss." In addition, Schmidt's (1994) notion of noticing formulated in his Noticing Hypothesis was also tapped since underlining was expected to engage at least a minimum amount of awareness. To be precise, all the participants were primarily familiarized with the underlining procedure by the researcher (cf. Izumi/Bigelow 2000: 250).

To verify the homogeneity of the intact classes randomly selected for the purpose of the research, the LSD was used as a measure of homogeneity using CEPT. In the present study, due to the nature of the study, we used non-parametric tests of difference. For the experimental group, we used the Wilcoxon signed-rank test to examine the effect of noticing on the production of the learners. Mann-Whitney U test was applied to examine the statistical significance between the experimental group and the third comparison group. Kruskal-Wallis or $\mathrm{H}$ test was used to compare the groups involved in the research, with the alpha level set at .05 in all tests.

\section{$5 \quad$ Results}

The initial statistical analysis of the research results revealed a comprehensive picture of the groups and their related type of task under study. Because the application of normality tests on the data showed no normal distribution of the data, and since the samples were small-sized classes, we used the median and interquartile range as measures of central tendency and dispersion. The median for all the three groups under study (experimental group, comparison group 1, comparison group 2) are displayed in Table 1. As displayed in the table, the median score of the experimental group output 1 considerably increased in comparison with the same group's output 2 median score. The lowest median score was obtained by comparison group 2 which received no output-fronted activity and was a typical traditional paragraph writing class.

\begin{tabular}{|c|c|c|c|c|c|c|}
\hline Group & N & Minimum & Maximum & Mdn & IQR & Std. Error \\
\hline EG Output 1 & 23 & 3.00 & 18.00 & 9.00 & 4.00 & .6439 \\
EG Output 2 & 23 & 5.00 & 16.00 & 13.00 & 6.00 & .6740 \\
CG 1 Output & 19 & 4.00 & 20.00 & 10.00 & 6.00 & .9824 \\
CG 2 Output & 21 & 3.00 & 12.00 & 8.00 & 4.00 & .5066 \\
\hline
\end{tabular}

Table 1: Descriptive Statistics of the Groups under Study 


\section{$5.1 \quad$ Hypothesis 1}

In response to the first question of the present research, hypothesis 1 predicted that producing output-fronted tasks will enhance greater noticing of the target rhetorical structures contained in the input. Following the Noticing Hypothesis requirement of noticing as focal attention on the part of the learner, the noticing function of output for noticing as the gap between what a person wants to say and what s/he can say, and Izumi and Bigelow's (2000) use of underlining as an on-line measure of noticing, the participants underlining of the model passage was analyzed to address the noticing issue as an on-line measure. The EG, having produced their output 1 on contrast, received a model paragraph of contrast to underline. Similarly, the CG1 received the same model paragraph once producing a paragraph on a different non-contrast topic. Table 2 shows the statistics of the EG and CG underlining task.

\begin{tabular}{|c|c|c|c|c|c|}
\hline Group & $\mathbf{N}$ & Minimum & Maximum & Mdn & IQR \\
\hline Experimental & 22 & .57 & 1.00 & .8300 & .15147 \\
\hline Comparison & 19 & .05 & 1.00 & .5000 & .32951 \\
\hline
\end{tabular}

Table 2: EG and CG1 Underlining Score

The main supposition based on hypothesis 1 was whether underlining of the contrast-related words increased after the related output-fronted activities. Table 2 shows that the median of the experimental group ( $\mathrm{Mdn}=.800)$ exceeds the control group's median $(\mathrm{Mdn}=.500)$. To examine whether the difference between the Mdns obtained by the EG and CG was significant, we applied the Mann-Whitney Test (see Table 3a \& b for the test statistics).

\begin{tabular}{|l|c|c|c|c|}
\hline & CG Underlining & N & Mean Rank & Sum of Ranks \\
\hline EG Underlining & 1.00 & 22 & 26.34 & 579.50 \\
& 2.00 & 19 & 14.82 & 281.50 \\
& Total & 41 & & \\
\hline
\end{tabular}

Table 3a: Mean Ranks for the EG and CG Underlining

\begin{tabular}{|l|c|}
\hline & EG Underlining \\
\hline Mann-Whitney U & 91.500 \\
Wilcoxon W & 281.500 \\
Z & -3.092 \\
Asymp. Sig. (2-tailed) & .002 \\
\hline
\end{tabular}

a Grouping Variable: CG Underlining

Table 3b: Mann-Whitney Test Statistics for Underlining

The statistics showed that a significant difference emerged between the two groups.

\section{$5.2 \quad$ Hypothesis 2}

According to hypothesis 2 , the noticing function of output will significantly affect acquisition of rhetorical structures of contrast expository texts. In other words, the prediction based on the second hypothesis was: having noticed the input in terms of specific structures, learners would acquire the target structures, and consequently their production might improve. In this phase, the EG participants were required to produce a contrast related paragraph (Output 1), 
then they were presented with a model contrast paragraph enriched with contrast-related structures and words, and again they were required to rewrite their first output (Output 2). The results of the outputs produced by the EG participants are displayed in Table 4.

\begin{tabular}{|c|c|c|c|c|c|}
\hline EG & N & Minimum & Maximum & Mdn & IQR \\
\hline Output 1 & 23 & 3.00 & 18.00 & 9.00 & 4.00 \\
Output 2 & 23 & 5.00 & 16.00 & 13.00 & 6.00 \\
\hline
\end{tabular}

Table 4: Median Target-like Score of the EG Outputs

As Table 4 shows, the median of the output 2 for the EG participants ( $M d n=13.00)$ exceeded that of the participants' output $1(\mathrm{Mdn}=.900)$. The Wilcoxon signed-rank test was applied to find whether any statistically significant difference existed between the outputs produced by the EG participants (see Table 5a \& b).

\begin{tabular}{|ll|c|c|c|}
\hline & & N & Mean Rank & Sum of Ranks \\
\hline EG Output 2 - Output 1 score & Negative Ranks & $5(\mathrm{a})$ & 7.10 & 35.50 \\
& Positive Ranks & $18(\mathrm{~b})$ & 13.36 & 240.50 \\
& Ties & $0(\mathrm{c})$ & & \\
& Total & 23 & & \\
\hline
\end{tabular}

a outexp $2<$ output 1 score

b outexp $2>$ output 1 score

c outexp2 = output 1 score

Table 5a: The EG Output 1 \& Output 2 Ranks

\begin{tabular}{|c|c|}
\hline & outexp2 - output 1 score \\
\hline$Z$ & $-3.129(\mathrm{a})$ \\
Asymp. Sig. (2-tailed) & .002 \\
\hline
\end{tabular}

Table 5b: Wilcoxon Test Statistics

The test found a significant difference between the outputs produced by the participants in the EG.

\subsection{Hypothesis 3}

In this phase of the study, the third hypothesis was tested: The output-first group learners (EG) outperform the non-output-first pre-emptive group learners concerning the acquisition of targeted forms. In fact, the prediction was that the group producing a comparison-related output first was expected to exceed the non-output-first group only receiving the teacher's input (the preemptive comparison group). For this purpose, the CG2 (the preemptive comparison group) initially received the input in the form of explicit explanation of contrast paragraphs by the teacher in English followed by examples. Having received the preemptive input, the CG2 participants were required to produce a paragraph on contrast (Output). Table 6 displays the statistics related to the EG and CG2 outputs. 


\begin{tabular}{|c|c|c|c|c|c|}
\hline Group & N & Minimum & Maximum & Mdn & IQR \\
\hline EG Output 2 & 23 & 5.00 & 16.00 & 13.00 & 6.00 \\
\hline CG Output & 21 & 3.00 & 12.00 & 8.00 & 4.00 \\
\hline
\end{tabular}

Table 6: EG and CG2 Median scores

Table 6 indicates that the EG median is much higher than that of the CG. We applied the Mann-Whitney Test to examine whether the difference between the Mdns obtained by the EG and CG was significant (see Table 7a \& b for the test statistics).

\begin{tabular}{|l|c|c|c|c|}
\hline & Exp output2 & N & Mean Rank & Sum of Ranks \\
\hline Com2 output & 1.00 & 21 & 15.31 & 321.50 \\
& 2.00 & 23 & 29.07 & 668.50 \\
& Total & 44 & & \\
\hline
\end{tabular}

Table 7a: The EG \& CG2 Ranks

\begin{tabular}{|l|c|}
\hline & Com2 output \\
\hline Mann-Whitney U & 90.500 \\
Wilcoxon W & 321.500 \\
Z & -3.565 \\
Asymp. Sig. (2-tailed) & .000 \\
\hline
\end{tabular}

Table 7b: Mann-Whitney Test Statistics (a)

The test statistics reveals that the difference between the two groups was statistically significant (Asymp. Sig. 2-tailed $=.000$ ). The higher median of the EG and the statistically significant difference might be used to imply that the specific experimental of the atmosphere of the EG contributed to the outperforming of the participants in the study.

\section{Discussion}

The main research question motivating this study was to investigate whether or not noticing would produce significant acquisition of knowledge of the rhetorical structure of an academic contrast paragraph in English. To this end, the participants were divided into three groups: EG (contrast output1-input-contrst output2), CG1 (noncontrast output1-input-contrast output2), and CG2 (preemptive input-contrast output). Table 1 displays the general statistics of the three groups participating in the study.

The first research question investigated whether output-first-then-input activities promote learners' noticing the rhetorical structures of contrast paragraphs or not. The results of the non-parametric Mann-Whitney U test for two unrelated sample groups give strong support for a positive answer to this critical research question. A significant difference was found between the EG and the CG participants' underlining tasks (see Table 3a \& b for details). The result might be used to imply that the differing experimental conditions of the EG appear to contribute significantly to the extent of attention paid to and finally noticing the target rhetorical structures. In addition, Table 2 displays that the IQR of the EG participants (IQR = .15) was much less than that of the CG (.32). The result indicates that individual variation in terms of noticing the target rhetorical structures for the EG was considerably less than that of the CG. In other words, it reveals that the EG attention was much less dispersed than the CG participants. The lower IQR for the EG participants might be attributed to the task they did 
preceding the underlining task: producing a contrast-related paragraph. Taking the noticing function of output into account, it might be claimed that the participants output 1 functioned as noticing booster, and consequently increased learners' attention to the target structures. In fact, as a result of their output 1 , the learners recognized the gap in their knowledge, and for the gap to be bridged, they probably noticed the input they received immediately following their output.

The test result might be used to imply that the amount of noticing of the EG participants increased due to the gap of knowledge in learners interlanguage system. The EG participants' output 1 was used as a prompt to raise the learners' noticing their lack of necessary knowledge of contrast text structure and linguistic forms needed. The finding of the first research hypothesis might be used to confirm Swain's argumentation for the noticing function of output in language acquisition. Swain (1995) claimed that learners' output might function to help learners recognize the gap between what they want to say and what they can. Having noticed the gap, learners might internalize the specific structures in the input. (cf. Izumi 2002: 545-546).

The second hypothesis of the study examined whether the noticing function of output will significantly affect acquisition of rhetorical structures of contrast paragraphs. In fact, the prediction was that noticing promotes learners' internalization of targeted structures in the input. To this end, the EG participants output 2 was compared with their output 1 to investigate the difference between them. The results of non-parametric Wilcoxon signed-rank test for two related samples revealed a significant statistical difference between the groups (Asymp. Sig. 2-tailed .002, $\mathrm{p} \leq .05$ ). It might be concluded that the noticing resulting from the participants' recognized gap in their interlanguage system contributed to better internalization of some targeted rhetorical structures in the input. However, no significant difference was found between the EG output 2 and the CG1 output.

The supposition made by the third hypothesis was that the output-first group learners outperform the non-output-first group learners (pre-emptive group learners) concerning the acquisition of targeted forms. In other words, the hypothesis predicted that output-fronted activities result in higher performance than pre-emptive input activities traditionally applied in paragraph writing classes. To test the claim, the EG learners' output 2 was compared with that of the CG2. Applying Mann-Whitney U test, hypothesis 3 was supported in that the EG participants, with contrast output 1-input-output 2, displayed a significant gain in their accurate use of target rhetorical structures (Asymp. Sig. 2-tailed .000, $\mathrm{p} \leq .05$ ). In addition, in the present study, the median score of the EG was the highest $(\mathrm{Mdn}=13)$ and the lowest median score was related to the $\mathrm{CG} 2(\mathrm{Mdn}=8)$ which received no output-fronted activity. It might be argued that since the participants in the pre-emptive comparison group could not recognize the gap in their interlanguage system, they could not raise their awareness of the target structures in the input which itself resulted in lower gain of the structures of contrast. Moreover, it might be concluded that the type of teacher-generated noticing in pre-emptive activities would be less effective than learner-generated noticing which occurs as a result of learners recognizing the gap of knowledge in output-fronted activities. This finding was partially consistent with Izumi and Bigelow's (2000) study: "learners come to notice their linguistic problems when trying to produce language, which then prompts them to notice the gap between their IL form and the target form upon receiving relevant input".

\section{Conclusion}

This study made an attempt to explore a highly consequential but neglected aspect of classroom teaching of paragraph writing: the effect of output-fronted activities. The questions addressed in the present research might be answered in ways to support the centrality of 
noticing as one possible requirement for the acquisition of rhetorical structures of contrast paragraphs in English. In addition, this study confirmed the use of output-first-then-input activities to enhance learners' uptake of needed structures and forms in the input. To date, the findings of the present study might support Schmidt's Noticing Hypothesis and Swain's Comprehensible Output Hypothesis.

Finally, some methodological concerns are in order. Firstly, to tap learners noticing in the study, following Izumi/Bigelow (2000), we used underlining parts of the input. In the literature some criticisms have been put forward against precision and accuracy of underlining as an on-line measure of noticing. Considering the asserted shortcomings, the present research results related to underlining as a measure of noticing should be interpreted cautiously. Secondly, due to logistic considerations, the maximum length of experimentation time for each of the groups participating in the study was around 90 minutes. Clearly, within such brevity of experimentation and treatment, participants might be constrained to perform at their utmost ability. In addition, problems in selection of the participants into the study and the number of participants in each group negatively affect the validity of the results; consequently, care must be taken in generalization of the research results.

\section{References}

Al-Hejin, Bandar (2004): "Attention and awareness: Evidence from cognitive and second language acquisition research". Columbia University Working Papers in TESOL \& Applied Linguistics 4/1: 1-22.

Arnaudet, Martin L./Barrett, Mary Ellen (1981): Paragraph development: A guide for students of English as a second language. Englewood Cliffs, N. J.

Bärenfänger, Olaf et al. (2001): "On the functions of L2 speech production and related cognitive processes for the acquisition of L2 speech competence". Linguistik Online 8, $1 / 01$.

Doughty, Catherine J./Long, Michael H. (2004): The handbook of second language acquisition. Malden, Mass. et al. (= Blackwell handbooks in linguistics).

Ellis, Rod/Basturkmen, Helen/Loewen, Shawn (2001): "Preemptive focus on form in the ESL classroom". TESOL Quarterly 3/35: 407-431.

Ellis, Rod (2005): "Principles of instructed language learning". System 2/33: 209-224.

Hulstijn, Jan H./Schmidt, Richard (1994): Consciousness in second language learning. Amsterdam. (AILA Review 11).

Izumi, Shinichi/Bigelow, Martha (2000): "Does output promote noticing and second language acquisition?" TESOL Quarterly, 2/34: 239-273.

Izumi, Shinichi (2002): "Output, input enhancement, and the noticing hypothesis. An experimental study on ESL relativization". SSLA 4/24: 541-577.

Krashen, Stephen D. (1998): "Comprehensible output?". System 2/26: 175-182.

Lluna-Mateu, Francisco R. (2006): Development of Spanish L2 competence in a synchronous chatroom environment. The role of visually-enhanced recasts in fostering grammatical knowledge and changes in communicative language use. Dissertation, Louisiana State University.

Mackey, Alison (2006): "Feedback, noticing and instructed second language learning". Applied Linguistics 3/27: 405-430.

Mann, William C./Taboada, Maite (2006): "Applications of rhetorical structure theory". Discourse Studies 4/8: 567-588.

Morgan-Short, Kara/Bowden, Harriet Wood (2006): "Processing instruction and meaningful output-based instruction. Effects on second language development". SSLA 1/28: 31-65. 
Norris, John M./Ortega, Lourdes (2004): "Defining and measuring SLA". In: Doughty, Catherine J./Long, Michael H. (eds.) (2004): The Handbook of Second Language Acquisition. New York: 717-761.

Segalowitz, Norman S./P. Lightbown, Patsy M. (1999): "Psycholinguistic approaches to SLA". Annual Review of Applied Linguistics 19: 43-63.

Shehadeh, Ali (2003): "Learner output, hypothesis testing, and internalizing linguistic knowledge". System 2/31: 155-171.

Sharwood Smith, Michael (1994): Second language learning. Theoretical foundations. New York. 


\section{Appendix A}

The Model Contrast Paragraph used for Underlining

\section{Sample Contrast Paragraph}

\begin{tabular}{|l|l|l|}
\hline Surname: & Score: & \\
\hline Sex: & & \\
\hline
\end{tabular}

Direction: Read the following paragraph carefully and underline the parts you think would help you in writing similar paragraphs.

Even though Arizona and Rhode Island are both states of the U.S., they are strikingly different in many ways. For example, the physical size of each state is different. Arizona is large, having an area of 114,000 square miles, whereas Rhode Island is only about a tenth the size, having an area of only 1,214 square miles. Another difference is in the size of the population of each state. Arizona has about four million people living in it, but Rhode Island has less than one million. The two states also differ in the kinds of natural environments that each has. For example, Arizona is a very dry state, consisting of large desert areas that do not receive much rainfall every year. However, Rhode Island is located in a temperate zone and receives an average of 44 inches of rain per year. In addition, while Arizona is a landlocked state and thus has no seashore, Rhode Island lies on the Atlantic Ocean and does have a significant coastline.

\section{Appendix B}

Scoring Module for Contrast Paragraphs

\begin{tabular}{|c|c|c|}
\hline $\begin{array}{l}\text { Surname: } \\
\text { Male } \square \quad \text { Female } \square\end{array}$ & $\begin{array}{ll}\text { Output } 1 & \square \\
\text { Output } 2 & \square\end{array}$ & Total Score: \\
\hline
\end{tabular}

\begin{tabular}{|c|c|}
\hline $\begin{array}{l}\text { Topic } \\
\text { Sentence }\end{array}$ & 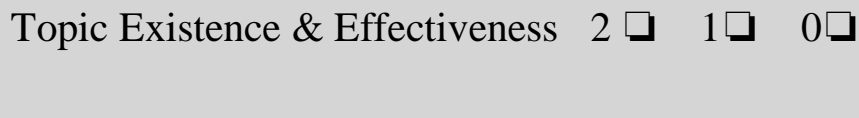 \\
\hline $\begin{array}{l}\text { Topic } \\
\text { Development }\end{array}$ & 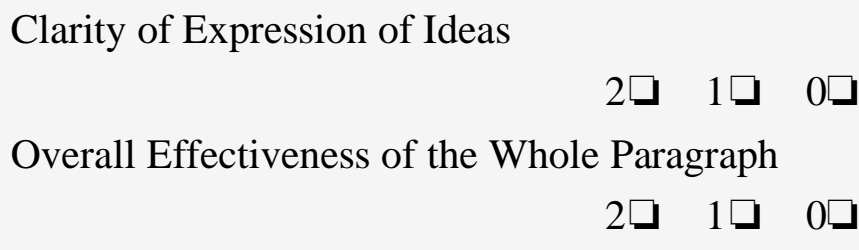 \\
\hline $\begin{array}{l}\text { Contrast-based } \\
\text { Structures and } \\
\text { items }\end{array}$ & $\begin{array}{ll}\text { Number of Error-free T-units } & \square \\
\text { Number of Unique Contrast Lexemes } & \square \\
\text { Number of Punctuation } & \square \\
\text { Number of Correlative Conjunctions } & \square \\
\text { Number of Predicate Structures } & \square \\
\text { Number of Sentence Connectors } & \square \\
\text { Number of Adjective/Prepositions } & \square\end{array}$ \\
\hline
\end{tabular}

